\title{
Kounis-Zavras Syndrome: from Pathogenesis to Management
}

\author{
Abdelkader Jalil El Hangouche ${ }^{1,2,3^{*}}$, Oumaima Alaika ${ }^{3}$, Nawal Doghmi ${ }^{3}$, Jamila Zarzur ${ }^{3}$, Taoufiq Dakka ${ }^{1}$ and \\ Mohammed Cherti ${ }^{3}$ \\ ${ }^{1}$ Faculty of medicine and pharmacy of Rabat, Mohamed V University, Morocco \\ ${ }^{2}$ Faculty of medicine and pharmacy of Tangier, Abdelmalek Essaadi University, Morocco \\ ${ }^{3}$ Department of Cardiology B, Mohamed V University, Morocco
}

Submission: July 17, 2017; Published: August 21, 2017

*Corresponding author: Abdelkader Jalil El Hangouche, Laboratory of physiology, Faculty of Medicine and Pharmacy of Rabat, Mohamed V University, Rabat, Morocco, Tel : 002126611545 15; Email: elhangouche.jalil@gmail.com

\begin{abstract}
The occurrence of acute coronary events in the setting of hypersensitivity reactions following an allergic insult defines the Kounis-Zavras syndrome that was described for the first time by Pfister in 1951 and published as the first description of allergic angina syndrome by Kounis and Zavras in 1991.

Since this topic has not been discussed in the international recommendations for cardiology, this review of Kounis-Zavras syndrome aims to provide an update on this rare clinical entity as well as to highlight the particularity and the special features of how to manage this syndrome.

Keywords: Kounis-Zavras syndrome; Myocardial ischemia; Allergy; Coronary spasm; Management
\end{abstract}

\section{Introduction}

Kounis syndrome refers to allergic acute myocardial ischemia in relation with release of inflammatory mediators by activated mast cell leading to coronary artery spasm and/or atheromatous plaque rupture or erosion [1]. This term is used either for allergic angina pectoris, the more frequent clinical presentation, or for allergic myocardial infarction which remains a rare complication [2]. Many conditions have been incriminated in inducing the kounis syndrome like drugs, foods; insect stings and environmental factors. We distinguish three variants of Kounis syndrome (I, II \& III) with different physiopathological assumptions and coronarographic profiles [1].

\section{"Kounis Zavras Syndrome": Variants and Pathogenesis}

The available data about the real incidence of Kounis Zavras syndrome comes from isolated clinical cases (almost 300) [3,4]. In the medical literature, three subtypes of Kounis syndrome have been described. Type I variant refers to category of patients without cardiovascular risk factors and with normal coronary arteries, in whom the acute allergic attacks induce coronary artery spasm causing either angina pectoris or acute myocardial infarction. [5,6] Type II variant occurs in patients with pre existing atheromatous coronary plaque disposed to erosion or rupture by acute allergic insult leading to acute myocardial infarction [7]. Type III variant is found in patients with hypersensitivity to the compound of nickel alloys, eluted drugs and polymers present in the stent that causes an inflammatory reaction a few days or weeks after the implementation of the stent leading to late pharmacoactive stent thrombosis $[4,5,8]$.

Several factors have been described to be incriminated in Kounis syndrome as drugs (antibiotic, analgesic, nonsteroidal anti-inflammatory, anticoagulant, corticosteroid,..) or environmental exposure (ant sting, bee sting, viper venom, wasp sting) [1,9]. It thought to explain the physiopathological process of Kounis synrdrome that many mediators (tryptase, chymase, histamine,...) are released by activated mast cells in cardiac tissue, coronary arteries and plaques while immunological reaction $[3,10]$. Histamine is the most important one with strong vasoconstrictive effects via H1- receptors [5]. Also, it was 
observed that the overproduction of cysteinyl leukotrienes and their receptors after Aspirin ingestion in context of aspirin atopy leads to acute myocardial ischemia, with or without elevated cardiac enzymes and troponin in patients with normal coronary artery, most likely by a vasospasm [11].

\section{Kounis Zavras Syndrome: Treatment and Management}

The difficulty of management of Kounis syndrome lies in the fact that the treatment of either of the two associated allergic and cardiac symptoms may worsen the other injury [12]. There is no consensus in terms of the treatment of allergic angina pectoris; therefore, the efficacy of the treatment is based on individual's cases report [3]. The management strategy of Kounis syndrome depends on its variant, thus, in patients with the type I variant, the intravenous hydrocortisone and antihistamines as treatment of the allergic event seems to be sufficient. Also, the calcium channel blockers and nitrates can be considered to reduce the coronary vasospasm. In patients with the type II variant, treatment consists on a acute coronary event strategy, with corticosteroids and antihistamines. Concerning the patients with the type III variant, a primary percutaneous coronary intervention should be performed with urgent aspiration of intransient thrombus $[13,14]$.

In Kounis Syndrome, the beta-blockers may interfere with the use of epinephrine which is the basis of treatment of anaphylaxis in so far as they can exaggerate coronary spasm due to an unopposed activity of $\alpha$-adrenergic receptors. Consequently, beta-blockers shouldn't be in Kounis syndrome $[13,15]$. The pharmacological adjunctive treatment of myocardial revascularization includes antithrombotic agents: acetylsalicylic acid and a P2Y12 receptor inhibitor; However, in the case of aspirin allergy, this drug must be avoided and substituted by alternative anti-platelet agents (as thienopyridines) [3,12].

\section{Kounis-Zavras Syndrome is Challenging}

Kounis syndrome remains a real challenge for the clinician since on one hand to date, there is no definitive guidelines and all current treatment strategies derive from published case reports, and on the other hand, the severity of clinical presentation involving Kounis syndrome range from angina pectoris with mild urticarian eruption to myocardial infarction with cardiogenik shock and anaphylaxis [16]. Therefore, it is crucial to consider the diagnosis of Kounis syndrome in patients presenting both cardiac and allergic insults simultaneously. Consequently, to optimize the patient prognosis and to treat the life-threating situations both quick recognition and medical intervention are needed and essential.

\section{Conclusion}

Today, allergic angina and allergic myocardial infarction are known as Kounis Syndrome. A variety of substances, medical conditions and environmental exposures are associated with this reaction. There is an exponential increase in the number of published articles reports on this syndrome, but the incidence is still not known. The pathogenesis involves histamine and other mast cell mediators leading to either vasospasm or acute plaque rupture and thrombus formation. The management of this syndrome includes therapy for vasospasm and anaphylaxis with the cautious use of epinephrine.

\section{References}

1. Schwartz BG, Daulat S, Kuiper J (2011) The Kounis-Zavras syndrome with the Samter-Beer triad. Proc (Bayl Univ Med Cent) 24(2): 107-109.

2. Fassio F, Kounis AF (2012) Syndrome (allergic acute coronary syndrome): different views in allergologic and cardiologic literature. Intern Emerg Med 7(6): 489-495.

3. Filippo F, Laura L, Dario AA, Silvia P, Gianni P, et al. (2015) Enrico Heffler Kounis syndrome: A concise review with focus on management. Eur J Intern Med 30: 7-10.

4. Velasco E, Díaz E, Avanzas P, José MR (2014) Acute stent thrombosis due to Kounis syndrome. International Journal of Cardiology 177: 698700 .

5. Shozo S, Yasuhiro S, Hirokazu H, Hiroaki K (2015) Kounis syndrome (allergic angina and allergic myocardial infarction) for cardiologists. Editorial / Journal of Cardiology Cases 12(4): 110-112.

6. Zhang L, Hui B, Feng Q (2015) An Extraordinary Case Associated with an Allergic Reaction to Clopidogrel: Coronary Artery Spasm or Kounis Syndrome? Heart, Lung and Circulation 24: e180-e183.

7. Nikolaidis LA, Kounis NG, Gradman AH (2002) Allergic angina and allergic myocardial infarction: a new twist on an old syndrome. Can J Cardiol 18(5): 508-511.

8. Chen JP, Hou D, Pendyala L, Goudevenos JA, Kounis NG (2009) Drugeluting stent thrombosis: the Kounis hypersensitivity-associated acute coronary syndrome revisited. JACC Cardiovasc Interv 2(7): 583-593.

9. Anthony C, Regis MD, Carl A, Germann MD, Jacob G, et al. (2015) Myocardial infarction in the setting of anaphylaxis to celecoxib: a case of kounis syndrome. The Journal of Emergency Medicine 49(2): e39-e43.

10. Gianluca C, Rita P, Alberto P, Laura P, Roberto F (2013) Kounis-Zavras syndrome presenting with ventricular arrhythmias and cardiogenic shock. Journal of Cardiology Cases 7(3): e74-e77.

11. Szczeklik A, Nizankowska E, Mastalerz L, Bochenek G (2002) Myocardial ischemia possibly mediated by cysteinyl leukotrienes. J Allergy Clin Immunol 109(3): 572-573.

12. Cevik C, Nugent K, Shome GP (2010) Treatment of Kounis syndrome. Int J Cardiol 143: 223-226.

13. Kounis NG (2013) Coronary hypersensitivity disorder: The Kounis syndrome. Clin Ther 35: 563-371.

14. Omri M, Kraiem H, Mejri O, Naija M, Chebili N (2017) Management of Kounis syndrome: two case reports J Med Case Rep 11(1): 145.

15. Ioannidis TI, Mazarakis A, Notaras SP, Karpeta MZ, Tsintoni AC, et al. (2007) Hymenoptera sting-induced Kounis syndrome: effects of aspirin and beta-blocker administration. Int J Cardiol 121: 105-108.

16. Tanboga IH, Karabay CY, Can MM, Akgün T, Güler A, et al. (2010) Kounis syndrome presenting with cardiogenic shock. J Cardiovasc Med 12(11): 833-836. 
This work is licensed under Creative Commons Attribution 4.0 License

DOI: 10.19080/JOCCT.2017.06.555700
Your next submission with Juniper Publishers will reach you the below assets

- Quality Editorial service

- Swift Peer Review

- Reprints availability

- E-prints Service

- Manuscript Podcast for convenient understanding

- Global attainment for your research

- Manuscript accessibility in different formats

( Pdf, E-pub, Full Text, Audio)

- Unceasing customer service

Track the below URL for one-step submission https://juniperpublishers.com/online-submission.php 